\title{
Business Cycle and Financial Cycle Spillovers in the G7 Countries
}

\author{
Nikolaos Antonakakis ${ }^{\mathrm{a}, \mathrm{b}, *}$, Max Breitenlechner ${ }^{\mathrm{c}}$, Johann Scharler ${ }^{\mathrm{c}}$ \\ ${ }^{a}$ Vienna University of Economics and Business, Department of Economics, Institute for International \\ Economics, Welthandelsplatz 1, 1020, Vienna, Austria. \\ ${ }^{b}$ University of Portsmouth, Department of Economics and Finance, Portsmouth Business School, Portland \\ Street, Portsmouth, PO1 3DE, United Kingdom. \\ ${ }^{c}$ University of Innsbruck, Department of Economics, Universitaetsstrasse 15, A-6020 Innsbruck, Austria.
}

\begin{abstract}
In this study we examine the dynamic interactions between credit growth and output growth using the spillover index approach of Diebold and Yilmaz (2012). Based on quarterly data on credit growth and GDP growth over the period 1957Q1-2012Q4 for the G7 countries we find that: (i) spillovers between credit growth and GDP growth evolve rather heterogeneously over time and across countries, and increase during extreme economic events. (ii) Spillovers between credit growth and GDP growth are of bidirectional nature, indicating bidirectional spillovers of shocks between the financial and the real sector. (iii) In the period shortly before and during the global financial crisis, the link between credit growth and GDP growth becomes more pronounced. In particular, the financial sector plays a dominant role during the early stages of the crisis, while the real sector quickly takes over as the dominant source of spillovers. (iv) Interestingly, credit growth in the US is the dominant transmitter of shocks to the G7 countries, and especially to other G7 countries' real sectors in the run up period to (and during) the global financial crisis. Overall, our results suggest that the magnitude and direction of spillovers between financial cycles and business cycles vary over time along with changes in the economic environment in the G7 countries.
\end{abstract}

Keywords: Business cycle, Financial cycle, Spillovers, Crisis, Recession JEL codes: C32; E32; E44; E51; F42

\footnotetext{
*Corresponding author. E-mail: nikolaos.antonakakis@wu.ac.at, phone: +431313 36 4133, fax: +431 31336904133 .
} 


\section{Introduction}

The view that macroeconomic and financial sector developments are closely interrelated has a long tradition and has received renewed interest in the aftermath of the 2008-2009 crisis. The implications of financial frictions for the business cycle and the interrelationship between the financial sector and real economic activity have been extensively studied (see for example, Bernanke et al., 1996, 1999; Bernanke and Gertler, 1989; Kiyotaki and Moore, 1997; Fostel and Geanakoplos, 2008; Brunnermeier, 2009; Brunnermeier and Pedersen, 2009; Gertler and Kiyotaki, 2010; Jermann and Quadrini, 2012, among many others). Empirically, Taylor and Schularick (2012) show that credit growth is a predictor of financial crises. ${ }^{1}$ Recessions which are associated with financial disruptions are generally deeper and last longer (see also Claessens et al., 2012; Jordà et al., 2013). ${ }^{2}$

Yet, the aforementioned studies on the link between real credit growth and real GDP growth have so far confined themselves to static analyses. The purpose of this paper is to examine the time-varying relationship between real credit growth and real GDP growth at business cycle frequencies for each of the G7 countries. To do so, we apply the VAR-based spillover index approach recently introduced by Diebold and Yilmaz (2009, 2012). This methodology allows us to decompose spillovers into those coming from (or to) a particular fundamental source and thus, to identify the main recipients and transmitters of shocks. The dynamic evolution of the importance of finance cycle and business cycle spillover effects can be assessed using a rolling window estimation and illustrated using spillover plots. The spillover methodology, which was originally applied to study the interaction between asset returns (Diebold and Yilmaz, 2009, 2012), has already attracted significant attention. For instance, it has been applied successfully to exchange rates (McMillan and Speight, 2010; Bubák et al., 2011; Antonakakis, 2012), equity markets (Yilmaz, 2010; Zhou et al., 2012), sovereign bond yield spreads (Antonakakis and Vergos, 2013), business cycles, growth and

\footnotetext{
${ }^{1}$ Mendoza and Terrones (2008) and Gourinchas and Obstfeld (2011) provide similar studies with empirical evidence pointing in the same direction. See also Martin and Rey (2006) for international aspects.

${ }^{2}$ A related, although somewhat distinctive branch of the literature studies the impact of structural credit supply shocks on the business cycle (see for example Buch and Neugebauer, 2011; Helbling et al., 2011; Peersman, 2011; Gambetti and Musso, 2012; Meeks, 2012; Hristov et al., 2012).
} 
volatility spillovers (Yilmaz, 2009; Antonakakis and Badinger, 2012), and money supply and financial asset spillovers (Cronin, 2014).

In line with Koop et al. (1996), Pesaran and Shin (1998) and Diebold and Yilmaz (2012), our analysis is based on a generalized vector autoregressive framework (VAR), in which forecast-error variance decompositions are invariant to the ordering of the variables. ${ }^{3}$ In the context of the present study, this is particularly important since it is difficult, if not impossible, to justify one particular causal ordering of the variables. Theoretical, as well as empirical contributions, suggest that credit growth and changes in real economic activity are strongly intertwined with causality potentially running in both directions.

Of course, the generalized VAR framework has advantages as well as drawbacks. A disadvantage is that it aggravates the identification of causal effects in a strict sense in the impulse response analysis. Nevertheless, by fully accounting for the pattern of observed correlation between shocks it increases the relevance from a policy perspective in light of the increased synchronization of shocks between credit growth and the business cycle. Based on the aforementioned considerations, we employ the generalized version of the spillover methodology of Diebold and Yilmaz (2012).

We find that the strength of spillover effects between credit growth and real GDP growth varies strongly across the G7 countries and over time. While Germany, Japan and the US exhibit reasonably high spillover effects between credit growth and output growth with around 20 percent in total and with approximately 30 percent between financial and real sectors, Canada, France, Italy and the UK are characterized by total spillover effects of below 10 percent. However, credit growth is as much a sender as it is a receiver of spillovers in each country. We also find that spillovers increase during recession periods. Finally, the analysis of spillover effects among the G7 economies suggests that the US is at the epicentre of the credit shocks transmission to other G7 countries' financial and real sectors before and during the global financial crisis.

The paper is organized as follows. Section 2 discusses the application of the spillover

\footnotetext{
${ }^{3}$ In contrast to a Cholesky-factor identification, which was originally used in the spillover analysis (see Diebold and Yilmaz, 2009).
} 
index approach so as to disentangle the intricate relationships between credit growth and GDP growth and outlines the data used. Section 3 presents the empirical findings. Section 4 summarizes the results and concludes this study.

\section{Empirical Methodology and Data}

\subsection{Measuring Spillovers}

The spillover index approach introduced by Diebold and Yilmaz (2009) builds on the seminal work on VAR models by Sims (1980) and the well-known notion of variance decompositions. This approach allows an assessment of the contributions of shocks to variables to the forecast error variances of both the respective and the other variables of the model. Using a rolling-window estimation, the evolution of spillover effects can be traced over time and illustrated by spillover plots. For the purpose of the present study, we use the variant of the spillover index in Diebold and Yilmaz (2012), which extends and generalizes the methodology introduced in Diebold and Yilmaz (2009).

The starting point for the analysis is the following $P$-th order, $K$-variable VAR

$$
y_{t}=\sum_{p=1}^{P} \Theta_{i} y_{t-i}+\varepsilon_{t},
$$

where $y_{t}=\left(y_{1 t}, y_{2 t}, \ldots, y_{K t}\right)$ is a vector of $K$ endogenous variables, $\Theta_{i}, i=1, \ldots, P$, are $K \times K$ parameter matrices and $\varepsilon_{t} \sim(0, \Sigma)$ is vector of disturbances that are independently distributed over time; $t=1, \ldots, T$ is the time index and $k=1, \ldots, K$ is the variable index.

Fundamental to the dynamics of the system is the moving average representation of model (1), which is given by $y_{t}=\sum_{j=0}^{\infty} A_{j} \varepsilon_{t-j}$, where the $K \times K$ coefficient matrices $A_{j}$ are recursively defined as $A_{j}=\Theta_{1} A_{j-1}+\Theta_{2} A_{j-2}+\ldots+\Theta_{p} A_{j-p}$, where $A_{0}$ is the $K \times K$ identity matrix and $A_{j}=0$ for $j<0$.

Following Diebold and Yilmaz (2012) we use the generalized VAR framework of Koop et al. (1996) and Pesaran and Shin (1998), which produces variance decompositions invariant to the variable ordering. According to this framework, the $H$-step-ahead forecast error variance decomposition is

$$
\phi_{i j}(H)=\frac{\sigma_{j j}^{-1} \sum_{h=0}^{H-1}\left(e_{i}^{\prime} A_{h} \Sigma e_{j}\right)^{2}}{\sum_{h=0}^{H-1}\left(e_{i}^{\prime} A_{h} \Sigma A_{h}^{\prime} e_{i}\right)},
$$


where $\Sigma$ is the (estimated) variance matrix of the error vector $\varepsilon, \sigma_{j j}$ the (estimated) standard deviation of the error term for the $j$-th equation and $e_{i}$ a selection vector with one as the $i$-th element and zeros otherwise. This yields a $K \times K$ matrix $\phi(H)=\left[\phi_{i j}(H)\right]_{i, j=1, \ldots K}$, where each entry gives the contribution of variable $j$ to the forecast error variance of variable $i$. The main diagonal elements contains the (own) contributions of shocks to the variable $i$ to its own forecast error variance, the off-diagonal elements show the (cross) contributions of the other variables $j$ to the forecast error variance of variable $i$.

Since the own and cross-variable variance contribution shares do not sum to one under the generalized decomposition, i.e., $\sum_{j=1}^{K} \phi_{i j}(H) \neq 1$, each entry of the variance decomposition matrix is normalized by its row sum, such that

$$
\tilde{\phi}_{i j}(H)=\frac{\phi_{i j}(H)}{\sum_{j=1}^{K} \phi_{i j}(H)}
$$

with $\sum_{j=1}^{K} \tilde{\phi}_{i j}(H)=1$ and $\sum_{i, j=1}^{K} \tilde{\phi}_{i j}(H)=K$ by construction.

This ultimately allows to define a total (volatility) spillover index as

$$
T S(H)=\frac{\sum_{i, j=1, i \neq j}^{K} \tilde{\phi}_{i j}(H)}{\sum_{i, j=1}^{K} \tilde{\phi}_{i j}(H)} \times 100=\frac{\sum_{i, j=1, i \neq j}^{K} \tilde{\phi}_{i j}(H)}{K} \times 100,
$$

which gives the average contribution of spillovers from shocks to all (other) variables to the total forecast error variance.

This approach is quite flexible and allows to obtain a more differentiated picture by considering directional spillovers: Specifically, the directional spillovers received by variable $i$ from all other variables $j$ are defined as

$$
D S_{i \leftarrow j}(H)=\frac{\sum_{j=1, j \neq i}^{K} \tilde{\phi}_{i j}(H)}{\sum_{i, j=1}^{K} \tilde{\phi}_{i j}(H)} \times 100=\frac{\sum_{j=1, j \neq i}^{K} \tilde{\phi}_{i j}(H)}{K} \times 100
$$

and the directional spillovers transmitted by variable $i$ to all other variables $j$ as

$$
D S_{i \rightarrow j}(H)=\frac{\sum_{j=1, j \neq i}^{K} \tilde{\phi}_{j i}(H)}{\sum_{i, j=1}^{K} \tilde{\phi}_{j i}(H)} \times 100=\frac{\sum_{j=1, j \neq i}^{K} \tilde{\phi}_{j i}(H)}{K} \times 100 .
$$

Notice that the set of directional spillovers provides a decomposition of total spillovers into those coming from (or to) a particular source. 
By subtracting Equation (5) from Equation (6) the net spillover from variable $i$ to all other variables $j$ are obtained as

$$
N S_{i}(H)=D S_{i \rightarrow j}(H)-D S_{i \leftarrow j}(H)
$$

providing information on whether a country (variable) is a receiver or transmitter of shocks in net terms. Put differently, Equation (7) provides summary information about how much each market contributes to the volatility in other markets, in net terms.

Overall, the spillover index approach provides measures of the intensity of interdependences across countries and variables and allows a decomposition of spillover effects by source and recipient.

In the context of the present study, we posit the following hypothesis: The direction and magnitude of spillovers between financial cycles and business cycles is time-varying and depends on global, as well as country-specific events. In particular, since the recent financial crisis, which originated in the US and lead to disruptions in the financial system and economic activity worldwide, we hypothesize that the US is at the epicentre of financial cycle spillovers during this period. Conversely, during the Asian financial crisis in 1997, we hypothesize that financial spillovers originating in Japan are more pronounced.

\subsection{Data description}

We collect quarterly data on domestic credit, Gross Domestic Product (GDP) and GDP deflator for the G7 countries over the period 1957Q1-2012Q4 from the International Financial Statistics database (IFS) of the International Monetary Fund (IMF). ${ }^{4}$ The values of all variables are taken at the start of each quarter. Domestic credit is defined as total claims of banks with national residency. To obtain the maximum length for each country we combine the two series "Domestic Credit" and "Domestic Claims" from the IFS dataset. The choice of the specific time period and countries is purely based on data availability and on the

\footnotetext{
${ }^{4}$ Only for Canada's domestic credit, we prefer to use data from the Statistics Canada instead. This decision was mainly driven by the fact that: i) the IFS credit series for Canada ends already in 2008Q4 and ii) in 2001Q4 the series jumps significantly due to changes in the definition of the variable (Canada adopted the IMF's "Monetary and Financial Statistics Manual 2000" in 2001).
} 
examination of financial cycles and business cycles among developed countries, respectively. See Table 1 for specific data availability in each country and a detailed list of each variable and its data source (including all specific table codes).

[Insert Table 1 about here]

We then deflate the credit and GDP series by the GDP deflator to obtain their real counterparts. Finally, we take the fourth differences of the natural logarithms of real credit and real GDP so as to obtain year-on-year real credit growth rates and real GDP growth rates, respectively. ${ }^{5}$

Descriptive statistics on year-on-year real credit growth and real GDP growth rates are presented in Table 2. The UK experienced the highest rate of real credit growth (56.39 percent) in the sample. Equivalently, Japan exhibits the highest growth rate of real GDP (15.39 percent). The countries' averages of real credit and real GDP growth lie within [3.46, 7.28] percent and $[1.33,4.35]$ percent, respectively. The range, as well as the relatively high standard deviations across the G7 countries, reveal a substantial variation within the variables.

[Insert Table 2 about here]

\section{Results}

\subsection{Spillovers between Credit Growth and Output Growth within countries}

In Table 3 we report estimates of the spillover indices for each country based on 12 quarters ahead forecast error variance decompositions. ${ }^{6}$ For each country, the $i j$-th entry, where $i$ and $j$ denote credit growth or output growth, is the estimated contribution to the forecast error variance of variable $i$ coming from innovations to variable $j$. Hence, the diagonal elements $(i=j)$ measure own-variable spillovers of output growth and credit growth

\footnotetext{
${ }^{5}$ We have also explored the robustness of our results based on the cyclical components of quarterly real GDP (credit), defined as deviation of the logged actual from potential GDP (credit); the latter is obtained as the Hodrick-Prescott filtered series of (the logarithm of) the countries real GDP (credit). These results are very similar to those presented below and thus omitted for the sake of brevity.

${ }^{6}$ The lag-length of the VAR specifications is based on the Akaike Information Critetion (AIC).
} 
within countries, while the off-diagonal elements $(i \neq j)$ capture cross-variable spillovers between output growth and credit growth. The total volatility spillover index defined in Equation (4) is approximately equal to the grand off-diagonal entry relative to the column sum including diagonals (or row sum including diagonals), expressed in percentage points.

\section{[Insert Table 3 here]}

Summarizing the information in Table 3, we see that the strength of spillovers between credit growth and output growth is rather heterogeneous across the G7 countries. Total spillovers are relatively high in Germany, Japan and in the US with total spillover indices of 36.5 percent, 25 percent and 21.8 percent respectively. In contrast, in the UK (7.7 percent) and Canada (7.6 percent) total spillovers are relatively low suggesting that credit growth and the business cycle are not as closely linked. In France and Italy the estimated values for the total spillover index are slightly higher with 9.7 percent and 9.4 percent, respectively.

Turning to the directional spillovers we see that countries with high total spillovers also have relatively high spillovers from credit growth to output growth ranging from 22.1 percent in Japan to 31.8 percent in Germany. In the US, credit growth contributes 27.8 percent to fluctuations in output growth. While these spillovers are quantitatively sizable, we also see that spillovers originating in the real sector of the economy have a substantial impact on the dynamics of credit with directional spillover indices of 15.8 percent in the US, 27.9 percent in Japan and 42.3 percent in Germany. In the remaining countries in our sample, directional spillovers are generally low with estimated directional spillover indices below 10 percent. The only exception is Italy, wherein the directional spillover index from output growth to credit growth is 14.4 percent.

Overall, we see that, throughout the countries in our sample, credit growth is as much a sender as it is a receiver of spillovers indicating bidirectional spillovers of shocks between the financial and the real sector.

Although the use of an average measure of financial and business cycle spillovers provides a good indication of the financial and business cycle transmission mechanism, it might mask interesting information on movements in spillovers due to secular features of financial and 
business cycles. Hence, we are very interested in examining how total and net spillovers evolve over time and whether they are affected by major economic events, such as the latest crisis. To achieve that, we estimate the model in Equation (1) using 50-quarter rolling windows and obtain the variance decompositions and spillover indices in a time-varying fashion. ${ }^{7}$ Figure 1 plots the time-varying total spillover indices for each country in our sample, based on the rolling window estimation.

\section{[Insert Figure 1 here]}

In Germany and the US, which are characterized by relatively high spillovers according to Table 3, we observe that, despite some fluctuations, total spillover indices are persistently high throughout the sample. In Japan, which according to Table 3 also has relatively high total spillovers, when we take the full sample into account, we see that total spillovers decline since around 2000 and amount to around 10 percent towards the end of the sample. Similarly, total spillovers also decline in Canada in the mid 1990s.

The most striking observation is, however, that around the onset of the recent financial crisis the total spillover indices increase in all countries with the exception of Japan. Thus, the link between the business cycle and credit growth becomes exceptionally pronounced during this period, suggesting that the financial sector was exceptionally strongly involved in the last recession. These results are in line with Helbling et al. (2011) who find that credit market shocks have been influential in driving global economic activity during the latest global recession.

Figure 2 shows the time varying net directional spillovers from credit growth to real GDP growth.

\section{[Insert Figure 2 here]}

\footnotetext{
${ }^{7}$ The choice of the 50-quarter rolling windows is based on the fact that we wish to capture time varying total and net spillovers of financial and business cycles. Given that 50-quarters correspond to 12.5 years, the 50 -quarter rolling windows adopted in this analysis seem to be long enough to capture the whole business cycle and the financial cycle (e.g. from the peak to through and back to the peak). However, for robustness purposes, we have also experimented using alternative $n$-quarter rolling windows (such as 30,40 and 60 quarters) and our conclusions reached have not been affected. These results are available upon request.
} 
In Canada, net spillovers are strongly positive in the 1980s and fluctuate around zero afterwards. In France and Germany, we observe mostly positive net spillovers until the late 2000s, whereas Italy is characterized by negative spillovers, expect a brief period in the mid 2000s. Net spillovers are negative in Japan since the early 1990s and turned into positive only recently. In the US we observe a similar pattern, although the increase in net spillovers is substantially more pronounced. And in the UK, net spillovers frequently change sign (see Figure 2).

Recall that, according to Figure 1, total spillovers strongly increase before and during the last recession in almost all countries. Looking at the time-varying net spillovers in Figure 2, we can explicitly identify the relationship between credit growth and output growth during this period. Conventional wisdom holds that the financial sector was a major driving force during the financial crisis in the US and the subsequent global downturn. In line with this view, we find that credit growth becomes a net transmitter in the US since the mid 2000s. Similarly, net spillovers turn positive in Japan towards the end of the sample. In Germany and Italy, credit growth is the dominant transmitter briefly during the onset of the global financial crisis, but net spillovers turn negative, indicating that through most of the crisis period, bank credit followed real economic developments in these countries. This observation is also true in Canada and, to a stronger extent, in France. In the UK, the pattern is less clear since net spillovers change signs frequently (see Figure 2).

Thus, in most countries, the financial sector played a dominant role during early stages of the recent financial crisis, while the real sector quickly took over as the dominant source of spillovers.

\subsection{Spillovers across Countries}

To examine whether credit expansions and contractions in one country spill over into other countries' real and financial sectors we now look at spillovers across the G7 countries. As it seems plausible that credit market conditions in one country can influence not only credit in other countries but also their growth rate of output, we estimate a VAR with credit growth and output growth variables for each country. We drop Italy due to the limited 
data availability. Based on a twelve-variable VAR, we then again conduct the spillover analysis. Table 4 presents these results. The total spillover index, which receives a value of 48 percent, shows that international spillovers appear to be quantitatively pronounced on average. More importantly, credit growth in the US is the dominant transmitter of shocks internationally, and especially to other countries' real sectors, followed by credit growth in Japan. For instance, innovations to credit growth in the United States explain 29.2 percent, 20.1 percent, 15.8 percent, 14.1 percent and 6.8 percent of the 12-quarter forecast error variance of output growth in Canada, UK, Germany, France and Japan, respectively. In addition, innovations to credit growth in the United States explain 1.6 percent, 1.9 percent, 0.9 percent, 0.6 percent and 2.1 percent of the 12-quarter forecast error variance of credit growth in the aforementioned countries, respectively. Helbling et al. (2011) and Kollmann et al. (2011) also find that credit shocks originating in the United States have a significant impact on the evolution of world growth during global recessions. In addition, our results suggest that US credit growth is also responsible for the magnification of spillovers within and between countries' real and (to lesser extend) financial sectors. Thus, in this study, we find that the importance of the role financial factors play in the modern business cycle (as documented by Jordà et al., 2013) is heterogeneous over the phase of the business cycle.

\section{[Insert Table 4 here]}

Turning our attention to the evolution of total spillovers across the G6 countries over time, we observe according to Figure 3 that total spillovers are considerably high and become exceptionally pronounced, reaching a peak during extreme economic events, such as the 1987 stock market crash, the Asian crisis and the Great Recession of 2007-2009. This result is in line with the findings of Claessens et al. (2012) and Jordà et al. (2013), that indicate a mutually negative influence of financial turmoil and economic recessions.

\section{[Insert Figure 3 here]}

Figure 4 shows the time-varying net directional spillovers from credit growth and real GDP growth across the G6 countries. 
[Insert Figure 4 here]

Overall, the results are very revealing, when we consider the link of credit growth and GDP growth spillovers across the G7 countries and (financial and real) sectors simultaneously. In particular, the dominance of the credit growth spillovers in net terms becomes extremely less pronounced across the G6 countries and sectors, with the only exception of Japan, wherein net spillovers from credit growth during the Asian crisis reached around $50 \%$. Interestingly, the US was a net receiver of credit growth spillovers till the beginning of 2000 and became a net transmitter of credit growth shocks in the run up to (and during) the global financial crisis and until 2010. After 2010, US GDP growth spillovers in net terms became the dominant factors of contagion and magnification of shocks, thus gaining particular importance in the simultaneous feedback effects across the G6 countries' real and financial sectors. This suggest that credit growth in the US since the 2000s might have contributed to the 2007-2009 global financial crisis. The shock in the financial sector was then transmitted to the real sector which was then fed back to the financial sector creating rippling effects within and between the G7 countries.

\section{Conclusions}

In this paper, we study the time-varying (dynamic) relationship between credit growth and real GDP growth at business cycle frequencies for each of the G7 countries using the spillover index of Diebold and Yilmaz (2012). This technique is perfectly suited to address the potential bidirectional spillovers of shocks between credit growth and output growth.

We find several stylized facts, which are consistent with existing studies. First, the link between credit growth and real GDP growth particularly tightens during crises periods. This result is consistent with the studies from Claessens et al. (2012) and Jordà et al. (2013), which indicate a mutually negative influence of financial turmoil and economic recessions. Our analysis reveals that during such periods, spillovers increase between sectors and also across G7 countries. Secondly, credit growth is as much a sender as it is a receiver of spillover shocks, confirming the bidirectional spillovers of shocks between the two sectors. Thirdly, 
credit growth in the US is a dominant international transmitter of shocks and especially to other countries real sectors. This pattern is most pronounced during the last global financial crisis. Similarly, Helbling et al. (2011) detect adverse effects of US credit shocks on the business cycles of the G7 countries during the recent financial crisis.

Furthermore, in the run up period to the global financial crisis, credit growth is a transmitter of shock spillovers in most of the countries in our sample. However, with the start of the crisis, shocks of real GDP growth become relatively more pronounced. An exception is the US economy, where the financial sector is a permanent transmitter of net spillovers of shocks within the US and across the G6 economies during the aforementioned periods.

Finally, the strength and direction of spillover effects evolves rather heterogonously across the G7 countries. In particular, we detected a group of countries with especially high spillover effects (i.e. Germany, Japan and the US), and another group of countries (i.e. Canada, France, Italy and the UK) with relatively low spillover effects between the financial sector and the real sector.

Future research along these lines is thus called for, so as to clarify these particular differences in the dynamic evolution of spillovers between credit cycles and business cycles.

\section{Acknowledgements}

The authors would like to thank the editor, Prof. Hadi Salehi Esfahani, and the anonymous reviewer for their constructive comments and suggestions which helped us to improve the scope and clarity of the paper. The usual disclaimer applies.

\section{References}

Antonakakis, N., 2012. Exchange return co-movements and volatility spillovers before and after the introduction of euro. Journal of International Financial Markets, Institutions and Money 22 (5), 1091-1109.

Antonakakis, N., Badinger, H., 2012. Output volatility, economic growth, and cross-country spillovers: New evidence for the Gr countries. Department of Economics Working Papers 141, Vienna University of Economics, Department of Economics.

Antonakakis, N., Vergos, K., 2013. Sovereign bond yield spillovers in the Euro zone during the financial and debt crisis. Journal of International Financial Markets, Institutions and Money 26, 258-272.

Bernanke, B., Gertler, M., 1989. Agency costs, net worth, and business fluctuations. The American Economic Review 79 (1), 14-31.

Bernanke, B., Gertler, M., Gilchrist, S., 1996. The financial accelerator and the flight to quality. The Review of Economics and Statistics 78 (1), 1-15. 
Bernanke, B., Gertler, M., Gilchrist, S., 1999. The financial accelerator in a quantitative business cycle framework. In: Taylor, J. B., Woodford, M. (Eds.), Handbook of Macroeconomics. Vol. 1 of Handbook of Macroeconomics. Elsevier, Ch. 21, pp. 1341-1393.

Brunnermeier, M. K., 2009. Deciphering the liquidity and credit crunch 2007-2008. The Journal of Economic Perspectives 23 (1), 77-100.

Brunnermeier, M. K., Pedersen, L. H., 2009. Market liquidity and funding liquidity. Review of Financial Studies 22 (6), 2201-2238.

Bubák, V., Kocenda, E., Zikes, F., 2011. Volatility transmission in emerging european foreign exchange markets. Journal of Banking $\&$ Finance 35 (11), 2829-2841.

Buch, C. M., Neugebauer, K., 2011. Bank-specific shocks and the real economy. Journal of Banking $\&$ Finance 35 (8), 2179-2187.

Claessens, S., Kose, M. A., Terrones, M. E., 2012. How do business and financial cycles interact? Journal of International Economics 87 (1), 178-190.

Cronin, D., 2014. The interaction between money and asset markets: A spillover index approach. Journal of Macroeconomics 39 (A), 185-202.

Diebold, F. X., Yilmaz, K., 2009. Measuring financial asset return and volatility spillovers, with application to global equity markets. Economic Journal 119 (534), 158-171.

Diebold, F. X., Yilmaz, K., 2012. Better to give than to receive: Predictive directional measurement of volatility spillovers. International Journal of Forecasting 28 (1), 57-66.

Fostel, A., Geanakoplos, J., 2008. Leverage cycles and the anxious economy. American Economic Review 98 (4), 1211-1244.

Gambetti, L., Musso, A., Sep 2012. Loan supply shocks and the business cycle. Working Paper Series 1469, European Central Bank.

Gertler, M., Kiyotaki, N., 2010. Financial Intermediation and Credit Policy in Business Cycle Analysis. In: Friedman, B. M., Woodford, M. (Eds.), Handbook of Monetary Economics. Vol. 3 of Handbook of Monetary Economics. Elsevier, Ch. 11, pp. 547-599.

Gourinchas, P.-O., Obstfeld, M., July 2011. Stories of the Twentieth Century for the Twenty-First. Working Paper 17252, National Bureau of Economic Research.

Helbling, T., Huidrom, R., Kose, M. A., Otrok, C., 2011. Do credit shocks matter? A global perspective. European Economic Review 55 (3), 340-353.

Hristov, N., Hülsewig, O., Wollmershäuser, T., 2012. Loan supply shocks during the financial crisis: Evidence for the euro area. Journal of International Money and Finance 31 (3), 569-592.

Jermann, U., Quadrini, V., 2012. Macroeconomic effects of financial shocks. American Economic Review $102(1), 238-271$.

Jordà, Ò., Schularick, M., Taylor, A. M., 2013. When credit bites back. Journal of Money, Credit and Banking 45 (s2), 3-28.

Kiyotaki, N., Moore, J., 1997. Credit cycles. Journal of Political Economy 105 (2), 211-248.

Kollmann, R., Enders, Z., Mller, G. J., 2011. Global banking and international business cycles. European Economic Review 55 (3), 407-426.

Koop, G., Pesaran, M. H., Potter, S. M., 1996. Impulse response analysis in nonlinear multivariate models. Journal of Econometrics 74 (1), 119-147.

Martin, P., Rey, H., 2006. Globalization and emerging markets: With or without crash? American Economic Review 96 (5), 1631-1651.

McMillan, D. G., Speight, A. E., 2010. Return and volatility spillovers in three euro exchange rates. Journal of Economics and Business 62 (2), 79-93.

Meeks, R., 2012. Do credit market shocks drive output fluctuations? Evidence from corporate spreads and defaults. Journal of Economic Dynamics and Control 36 (4), 568-584.

Mendoza, E. G., Terrones, M. E., May 2008. An Anatomy Of Credit Booms: Evidence From Macro Aggregates And Micro Data. Working Paper 14049, National Bureau of Economic Research.

Peersman, G., Dec 2011. Bank Lending Shocks and the Euro Area Business Cycle. Working Papers of Faculty of Economics and Business Administration, Ghent University, Belgium 11/766, Ghent University, Faculty 
of Economics and Business Administration.

Pesaran, H. H., Shin, Y., 1998. Generalized impulse response analysis in linear multivariate models. Economics Letters 58 (1), 17-29.

Sims, C., 1980. Macroeconomics and reality. Econometrica 48, 1-48.

Taylor, A. M., Schularick, M., 2012. Credit booms gone bust: Monetary policy, leverage cycles, and financial crises, 1870-2008. American Economic Review 102 (2), 1029-1061.

Yilmaz, K., 2009. International business cycle spillovers. Koc University-TUSIAD Economic Research Forum Working Papers 0903, Koc University-TUSIAD Economic Research Forum.

Yilmaz, K., 2010. Return and volatility spillovers among the East Asian equity markets. Journal of Asian Economics 21 (3), 304-313.

Zhou, X., Zhang, W., Zhang, J., 2012. Volatility spillovers between the Chinese and world equity markets. Pacific-Basin Finance Journal 20 (2), 247-270. 
Table 1: Data availability and sources

\begin{tabular}{|c|c|c|c|c|}
\hline Country & Variable & Data Availability & Source & Table Code \\
\hline \multirow[t]{3}{*}{ CAN } & Credit & 1957Q1-2012Q4 & Statistics Canada & 176-0015 \\
\hline & GDP & 1957Q1-2012Q4 & IMF-IFS & 156"99BAC"Q \\
\hline & GDP_def & 1957Q1-2012Q4 & IMF-IFS & 156" 99BIR"Q \\
\hline \multirow[t]{3}{*}{ FRA } & Credit & 1957Q1-2012Q4 & IMF-IFS & $132 " 32 " \mathrm{Q}$ \\
\hline & GDP & 1970Q1-2012Q3 & IMF-IFS & 132"99B_C"Q \\
\hline & GDP_def & 1970Q1-2012Q3 & IMF-IFS & 132"BIR"Q \\
\hline \multirow[t]{3}{*}{ GER } & Credit & 1957Q1-2012Q4 & IMF-IFS & $134 " 32 " \mathrm{Q}$ \\
\hline & GDP & 1960Q1-2012Q3 & IMF-IFS & 134"99B_C"Q \\
\hline & GDP_def & 1960Q1-2012Q3 & IMF-IFS & 134"BIR"Q \\
\hline \multirow[t]{3}{*}{ ITA } & Credit & 1970Q1-2012Q4 & IMF-IFS & $136 " 32 " \mathrm{Q}$ \\
\hline & GDP & 1980Q1-2012Q4 & IMF-IFS & 136"99B_C"Q \\
\hline & GDP_def & 1980Q1-2012Q4 & IMF-IFS & 136" BIR"Q \\
\hline \multirow[t]{3}{*}{ JAP } & Credit & 1957Q1-2012Q4 & IMF-IFS & $158 " 32 " \mathrm{Q}$ \\
\hline & GDP & 1957Q1-2012Q4 & IMF-IFS & 158"99BAC"Q \\
\hline & GDP_def & 1957Q1-2012Q4 & IMF-IFS & 158"99BIR"Q \\
\hline \multirow[t]{3}{*}{ UK } & Credit & 1959Q1-2012Q4 & IMF-IFS & $112 " 32 " \mathrm{Q}$ \\
\hline & GDP & 1957Q1-2012Q4 & IMF-IFS & 112"99B_C"Q \\
\hline & GDP_def & 1957Q1-2012Q4 & IMF-IFS & 112" 99BIR"Q \\
\hline \multirow[t]{3}{*}{ USA } & Credit & 1957Q1-2012Q4 & IMF-IFS & $111 " 32 " \mathrm{Q}$ \\
\hline & GDP & 1957Q1-2012Q4 & IMF-IFS & 111"99BAC"Q \\
\hline & GDP_def & 1957Q1-2012Q4 & IMF-IFS & 111"99BIR"Q \\
\hline
\end{tabular}

Note: GDP is seasonally adjusted; the base year of the GDP deflator is 2005. For Canada's domestic credit a different data source is used, because (i) the IFS series ends already in 2008Q4 and (ii) in 2001Q4 the series jumps significantly due to a change in the definition of the indicator (Canada adopted the IMF's "Monetary and Financial Statistics Manual 2000" in 2001). 


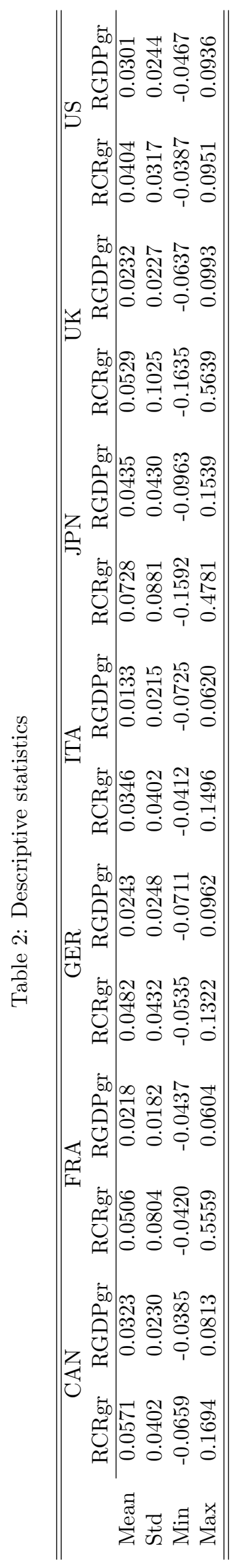


Table 3: Spillover table of real credit growth and real GDP growth within the G7

\begin{tabular}{|c|c|c|c|c|c|c|}
\hline \multirow[b]{3}{*}{ To (i) } & \multicolumn{3}{|c|}{ CANADA } & \multicolumn{3}{|c|}{ FRANCE } \\
\hline & \multicolumn{3}{|c|}{ From $(j)$} & \multicolumn{3}{|c|}{ From $(j)$} \\
\hline & CREDITgr & \multicolumn{2}{|c|}{ GDPgr } & CREDITgr & \multicolumn{2}{|c|}{ GDPgr } \\
\hline CREDITgr & 93.7 & \multicolumn{2}{|l|}{6.3} & 90.3 & \multicolumn{2}{|l|}{9.7} \\
\hline GDPgr & 8.8 & \multicolumn{2}{|l|}{91.2} & 9.2 & \multicolumn{2}{|l|}{90.8} \\
\hline Contr. to others & 8.8 & 6.3 & Total Spillover & 9.2 & 9.7 & Total Spillover \\
\hline \multirow[t]{3}{*}{ Contr. inc. own } & 101.5 & 97.5 & Index $=7.6 \%$ & 99.5 & 100.5 & Index $=9.4 \%$ \\
\hline & \multicolumn{3}{|c|}{ GERMANY } & \multicolumn{3}{|c|}{ ITALY } \\
\hline & & \multicolumn{3}{|c|}{ From $(j)$} \\
\hline To $(i)$ & CREDITgr & $\begin{array}{l}\text { From }(j) \\
\text { GDPgr }\end{array}$ & & CREDITgr & \multicolumn{2}{|c|}{ GDPgr } \\
\hline CREDITgr & 58.7 & \multicolumn{2}{|l|}{41.3} & 95.0 & \multicolumn{2}{|l|}{5.0} \\
\hline GDPgr & 31.8 & \multicolumn{2}{|l|}{68.2} & 14.4 & \multicolumn{2}{|l|}{85.6} \\
\hline Contr. to others & 31.8 & \multicolumn{2}{|r|}{ Total Spillover } & 14.4 & \multicolumn{2}{|r|}{ Total Spillover } \\
\hline Contr. inc. own & 89.5 & \multicolumn{2}{|c|}{$109.5 \quad$ Index $=36.5 \%$} & 109.4 & \multicolumn{2}{|r|}{ Index $=9.7 \%$} \\
\hline & \multicolumn{3}{|c|}{ JAPAN } & \multicolumn{3}{|c|}{ UK } \\
\hline & \multicolumn{3}{|c|}{ From $(j)$} & \multicolumn{3}{|c|}{ From $(j)$} \\
\hline To $(i)$ & CREDITgr & \multicolumn{2}{|c|}{ GDPgr } & CREDITgr & \multicolumn{2}{|c|}{ GDPgr } \\
\hline CREDITgr & 72.1 & 27.9 & & 91.6 & 8.4 & \\
\hline GDPgr & 22.1 & 77.9 & & 7.1 & 92.9 & \\
\hline Contr. to others & 22.1 & 27.9 & Total Spillover & 7.1 & 8.4 & Total Spillover \\
\hline Contr. inc. own & 94.2 & 105.8 & Index $=25.0 \%$ & 98.7 & 100.3 & Index $=7.7 \%$ \\
\hline & & US & & & & \\
\hline & & From & & & & \\
\hline To (i) & CREDITgr & GDPgr & & & & \\
\hline CREDITgr & 84.2 & 15.8 & & & & \\
\hline GDPgr & 27.8 & 72.2 & & & & \\
\hline Contr. to others & 27.8 & 15.8 & Total Spillover & & & \\
\hline Contr. inc. own & 112 & 88 & Index $=21.8 \%$ & & & \\
\hline
\end{tabular}

Note: The underlying variance decomposition is based on bivariate VARs (using 12-step-ahead forecasts) for each country. The spillover indices definition is given in Equations (2)-(7). 


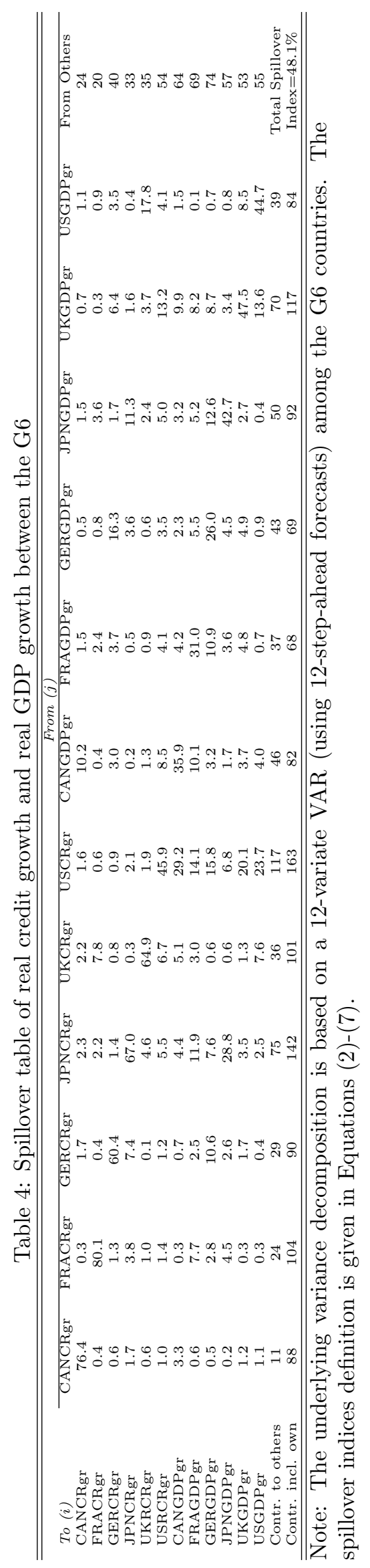


Figure 1: Total Spillovers of real credit growth and real GDP growth within the G7
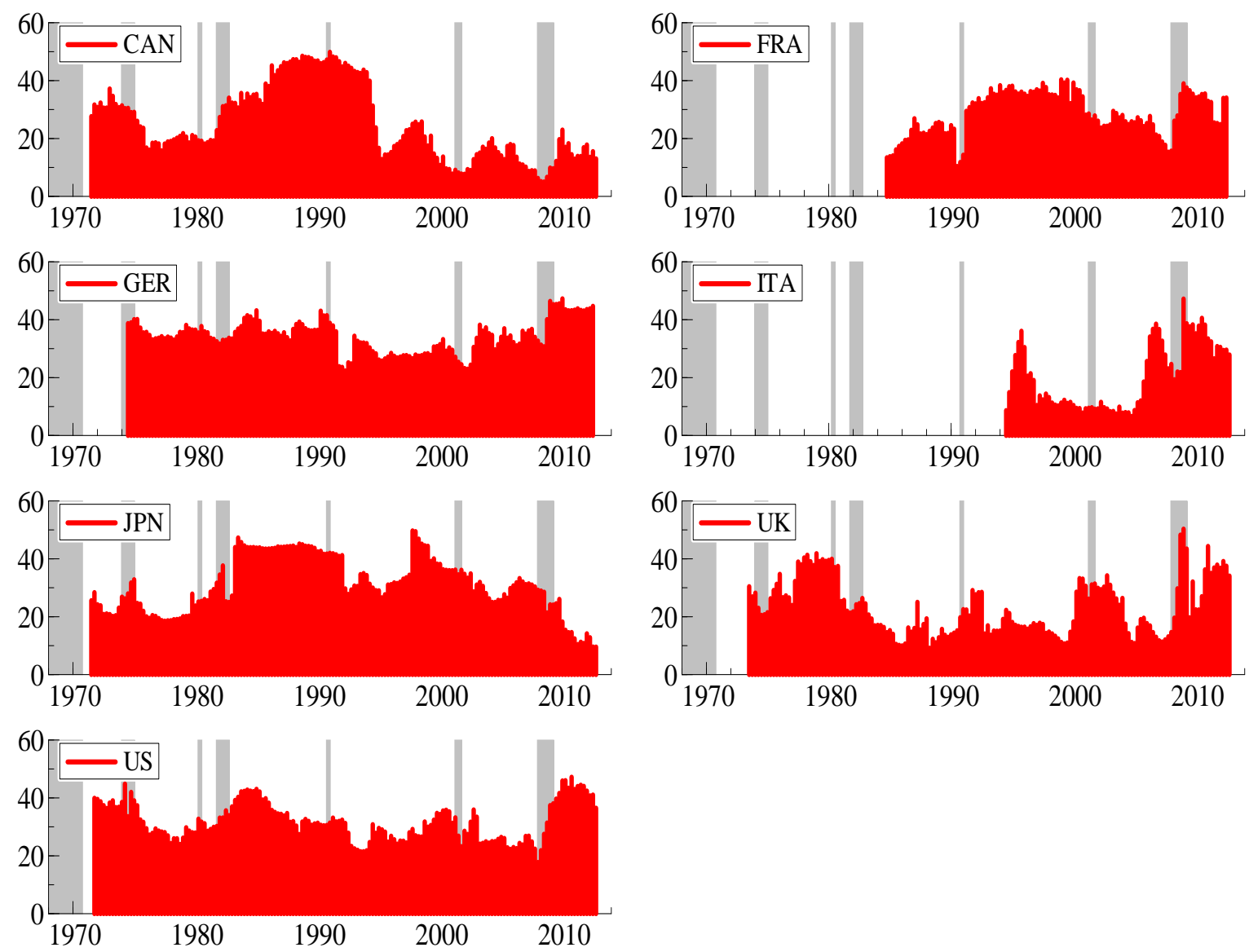

Note: Plots of moving total spillovers estimated using 50-quarter rolling windows. Thus the starting date of the total spillovers within each country is 50 quarters after the initial available date for that country (see also Table 1). Grey shading denotes US recessions as defined by the NBER. 
Figure 2: Net Spillovers between real credit growth and real GDP growth within the G7
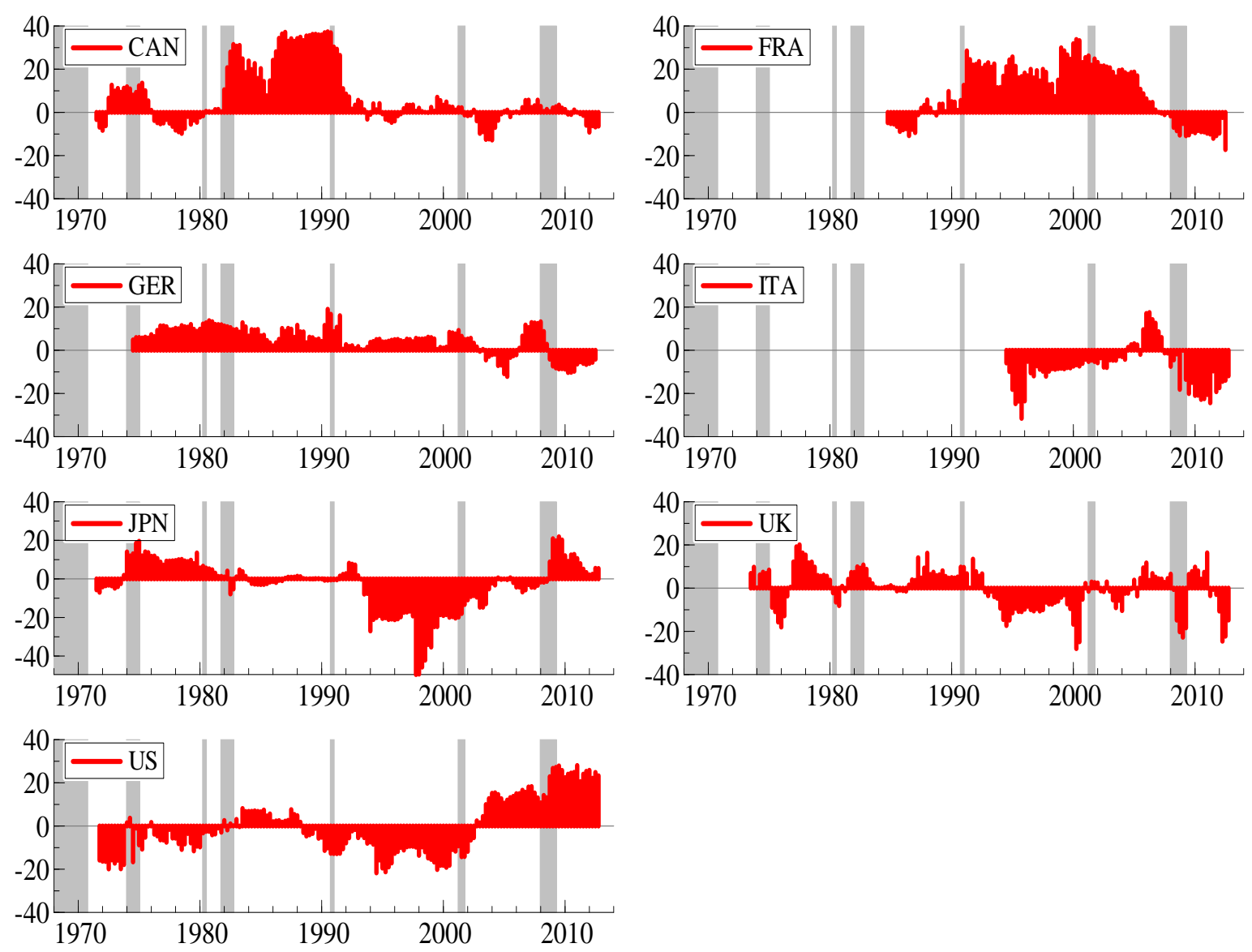

Note: Plots of moving net spillovers estimated using 50-quarter rolling windows. Thus the starting date of the net spillovers within each country is 50 quarters after the initial available date for that country (see also Table 1). Positive (negative) values indicate that credit growth is a net transmitter (receiver) of shocks to GDP growth. Grey shading denotes US recessions as defined by the NBER. 
Figure 3: Total Spillover of real credit and real GDP growth among the G6

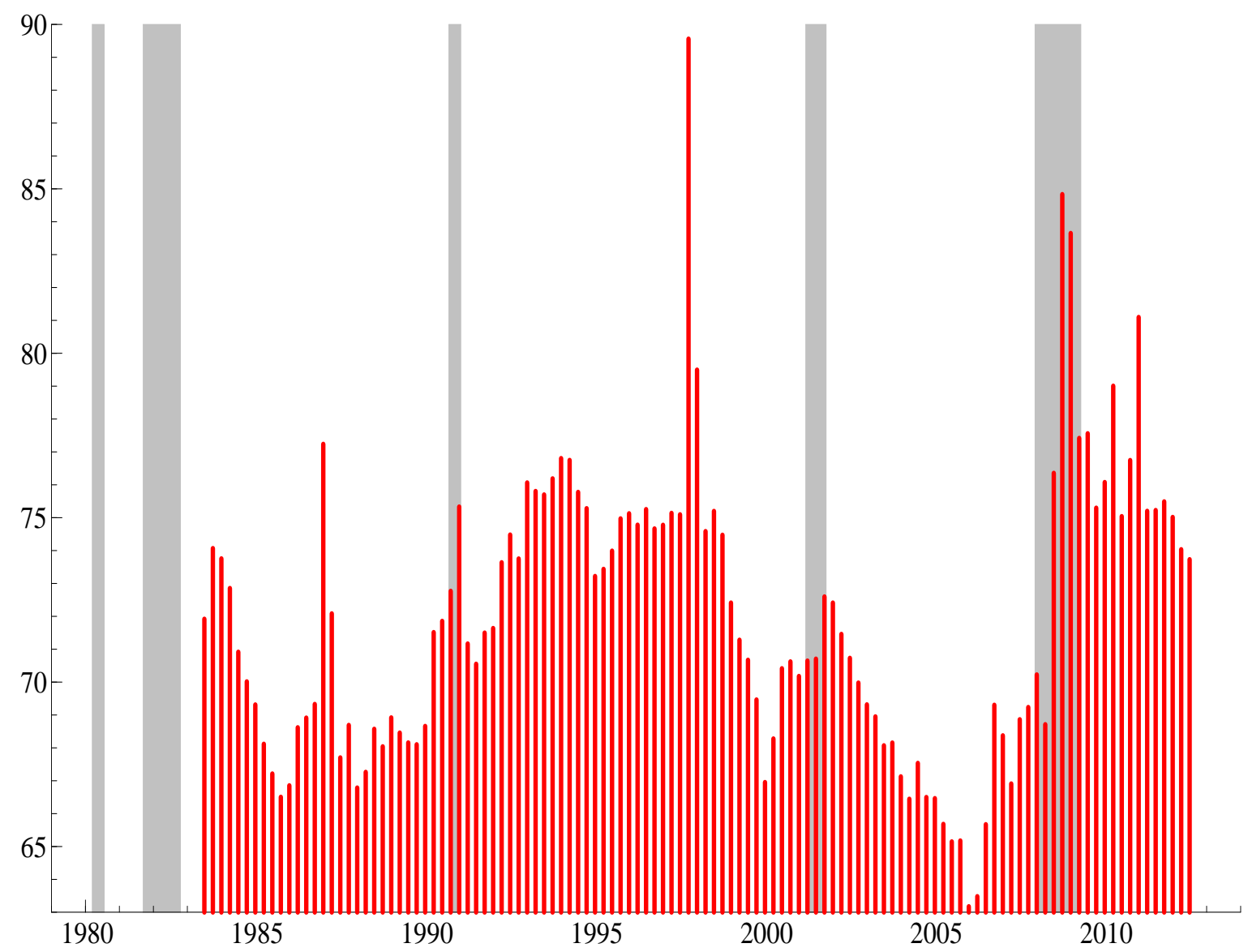

Note: Plot of the moving total spillover estimated using 50-quarter rolling windows. Thus the starting date of the total spillovers among the G6 countries is 50 quarters after the initial available date for all G6 countries (see also Table 1). Grey shading denotes US recessions as defined by the NBER. 
Figure 4: Net Spillovers between real credit and real GDP growth among the G6
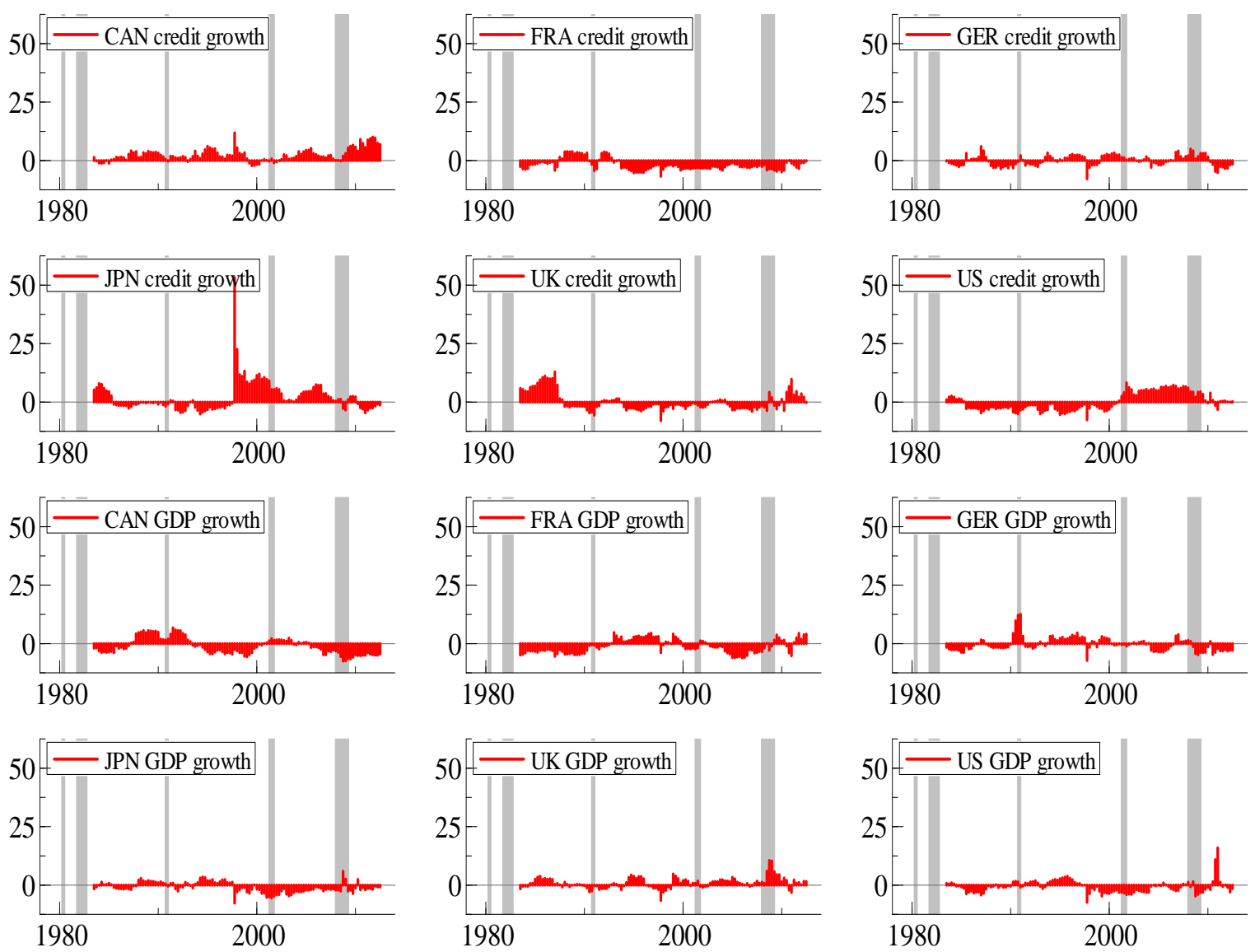

Note: Plot of the moving net spillover estimated using 50-quarter rolling windows. Thus the starting date of the net spillovers among the G6 countries is 50 quarters after the initial available date for all G6 countries (see also Table 1). Positive (negative) values indicate that the variable of interest is a net transmitter (receiver) of shocks to the rest of the variables in our analysis. Grey shading denotes US recessions as defined by the NBER. 